\title{
ENRAIZAMENTO DE ESTACAS LENHOSAS DE PORTA-ENXERTOS DE PEREIRA SOB NEBULIZAÇÃO INTERMITENTE ${ }^{1}$
}

\author{
IVES MASSANORI MURATA², WILSON BARBOSA, CARMEN SILVIA VIEIRA JANEIRO NEVES ${ }^{4}$, \\ JOAQUIM ANTONIO MARTINS FRANCO
}

\begin{abstract}
RESUMO - Pesquisou-se o enraizamento de estacas lenhosas dos porta-enxertos de pereira: Taiwan Nashi-C (Pyrus calleryana Decaisne), D’água ( $P$. communis L) e Manshu Mamenashi ( $P$. betulaefolia Bunge), na ausência de reguladores de crescimento. As estacas lenhosas, medindo $20 \mathrm{~cm}$ de comprimento e contendo de 3 a 4 gemas, foram submetidas aos tratamentos com e sem incisão na parte basal e mantidas por 60 dias em ambiente de nebulização intermitente. As estacas de 'Taiwan Nashi-C' e 'D'água' apresentaram 53,8 e 51,8 \% de enraizamento, respectivamente, nos tratamentos com e sem incisão. Em estacas de 'Manshu Mamenashi', verificaramse excesso de brotações foliares e índice de enraizamento quase nulo. O método de incisão na base das estacas influenciou significativamente no enraizamento do porta-enxerto 'D’água'.
\end{abstract}

Termos para indexação: propagação, pêra e porta-enxerto oriental

\section{ROOTING OF HARDWOOD CUTTINGS OF PEAR ROOTSTOCKS UNDER INTERMITTENT MIST CONDITION}

\begin{abstract}
The rooting of hardwood cuttings in three pear rootstocks: 'Taiwan Nashi-C'(Pyrus calleryana Decaisne), 'D'água' (Pyrus communis L) and 'Manshu Mamenashi' (Pyrus betulaefolia Bunge) without growth regulators. Wood cuttings with $20 \mathrm{~cm}$ long and $3-4$ buds were treated or not with a basal cut and manteined in intermittent mist condition for 60 days. The 'Taiwan Nashi-C' and 'D'água' presented 53,8 and 51,8\% of rooting, respectively, in treated and untreated cuttings. The 'Manshu Mamenashi' cuttings showed excessive bud bursting and almost no rooting. The basal cut was efficient on 'D'água' rootstock rooting.
\end{abstract}

Index terms: propagation, Pyrus and oriental rootstocks.

O consumo de pêra vem aumentando no mercado nacional. Com isso, nota-se novo estímulo no cultivo de pereiras, principalmente as do tipo asiática, em diversas regiões do Sul e Sudoeste do País. De acordo com Oliveira et al. (2000), existe a consciência de que se deve investir em novas tecnologias na cultura, objetivando aumentar a produção interna e, conseqüentemente, reduzir a importação brasileira de pêra, estimada em 130 mil toneladas anuais.

No Estado de São Paulo, há condições adequadas ao cultivo de pereiras mais adaptadas ao clima subtropical. No entanto, verifica-se carência de cultivares-copa e porta-enxertos rústicos, totalmente testados e recomendados para às condições climáticas paulistas. Dentre os diversos acessos, dois porta-enxertos de pereira têm sido pesquisados, 'Taiwan Nashi-C' (Pyrus calleryana Decaisne) e 'Manshu Mamenashi' ( $P$. betulaefolia Bunge) (Barbosa et al., 1998; Maeda et al., 1997). O grande interesse pela utilização desses porta-enxertos orientais, rústicos e vigorosos, deve-se à alta adaptação ao clima subtropical, tolerância a temperaturas elevadas e a solos úmidos e maldrenados, resistência a 'fire blight' (Erwinia amylovora) e ao ‘declínio’ e baixa sensibilidade a nematóides e pulgão-lanígero (Westwood, 1978; Childers \& Zwet, 1982; Masseron, 1989). A cultivar porta-enxerto D'água ( Pyrus communis L.), por sua vez, teve grande importância na cultura até fins da década de 80 , pois apresenta boa fixação do sistema radicular e média resistência a nematóides.

Diversos métodos de propagação podem ser empregados para a obtenção de mudas de pereiras. Destaca-se, no entanto, a estaquia de material lenhoso ou herbáceo, pela facilidade de formação de grande quantidade de mudas num curto espaço de tempo, com baixo custo e fácil execução. Além disso, as plantas originadas de estacas apresentam maior uniformidade do que as oriundas de sementes (Fachinello et al., 1995). O potencial de enraizamento das estacas depende das condições in-

1 (Trabalho 262/2000). Recebido: 04/12/2000. Aceito para publicação: 20/05/2002. Pesquisa integrante do subprojeto: "Conservação, caracterização e comportamento regional de cultivares do germoplasma IAC de frutíferas de clima temperado-subtropical".

2 Eng $^{\mathrm{o}}$ Agr $^{\mathrm{o}}$, Mestrando do Departamento de Agronomia, Universidade Estadual de Londrina (UEL). C. P. 6001, CEP 86051-99 Londrina, PR. email: ivesmurata@hotmail.com.

3 Biólogo, MSc, Bolsista do CNPq, Pesquisador Científico do Centro de Fruticultura, Instituto Agronômico (IAC). C.P. 28, CEP 13001-970 Campinas, SP. e-mail: wbarbosa@barao.iac.br

4 Eng ${ }^{\mathrm{a}}$ Agr ${ }^{\mathrm{a}}$, Dr ${ }^{\mathrm{a}}$, Professora Adjunta do Departamento de Agronomia, UEL. e-mail: csvjneve@uel.br

5 Eng ${ }^{0} \mathrm{Agr}^{-}$, Consultor Técnico, IAC 
TABELA 1 - Porcentagem média de enraizamento de estacas lenhosas de três cultivares porta-enxerto de pereira em ambiente de nebulização intermitente. Ribeirão Preto-SP, 2000

\begin{tabular}{ccr}
\hline Porta-enxertos & Estacascom & Estacas sem \\
\hline Taiman Nashi-C & cortebasal (\%) & corte basal $(\%)$ \\
D'água & 37,0 A b & 53,8 A a \\
M anshu M amenashi & 51,8 A a & 26,4 B b \\
\hline
\end{tabular}
$\mathrm{C} \mathrm{V}(\%)$ 21,46

\footnotetext{
${ }^{z}$ Valores são correspondentes às médias originais de quatro repetições, no entanto, as letras estão de acordo com os dados transformados em $\mathrm{y}=\operatorname{arco} \operatorname{seno} \sqrt{\frac{P}{100}}$

y Médias seguidas de mesma letra, minúscula na linha e maiúscula na coluna, não diferem entre si ao nível de significância de 5 \%.
}

ternas da planta-matriz e das condições ambientais a que elas são submetidas (Hartmann \& Kester et al., 1990).

O presente experimento foi realizado com o objetivo de se verificar o enraizamento de estacas lenhosas de três porta-enxertos de pereira, sob sistema de nebulização intermitente com e sem incisão na porção basal e na ausência de reguladores de crescimento.

As estacas lenhosas e enfolhadas das cultivares portaenxertos de pereira: Taiwan Nashi-C (P. calleryana D.), D'água (P. communis) e Manshu Mamenashi ( $P$. betulaefolia L.) foram coletadas em 10 de agosto de 1999, no lote de germoplasma de pereiras do Núcleo Experimental de Agronomia do Sudoeste, do Instituto Agronômico (IAC), situado no município Capão Bonito-SP. As estacas de $20 \mathrm{~cm}$ de comprimento, e contendo de 3 a 4 gemas vegetativas cada, receberam dois tratamentos: a) sem incisão; e b) com incisão; de 2 cm na base, em sentido longitudinal. Todo o material, plantado em vasos plásticos de $10 \mathrm{~cm}$ de altura contendo xaxim moído, permaneceu em casa de vegetação por 60 dias, em sistema de nebulização, com intervalos de cinco minutos. Após esse período, as estacas foram retiradas dos vasos e avaliadas quanto à porcentagem de enraizamento.

Adotou-se o delineamento experimental inteiramente ao acaso, sendo os tratamentos dispostos em esquema fatorial de 3 (porta-enxertos) ' 2 (com e sem incisão), com 4 repetições. Cada parcela foi constituída de doze estacas. Para as análises, os dados de percentagem foram transformados em $\mathrm{y}=\operatorname{arco}$ seno $\sqrt{P / 100}$, onde $\mathrm{P}$ representa a percentagem de enraizamento. Na comparação das médias, foi utilizado o teste de Tukey, ao nível de $5 \%$ de probabilidade.

As estacas dos porta-enxertos 'D'água' e 'Taiwan Nashi-C' apresentaram enraizamento significativamente superior a 'Manshu Mamenashi', com médias de 51,8 e 53,8 \% para tratamento com e sem incisão, respetivamente (Tabela 1). Antunes et al. (1996), mesmo utilizando ambiente nebulizado e dosagem de 2000 ppm de AIB, conseguiram enraizamento da ordem de 46\%, para estacas semilenhosas de 'Taiwan Nashi-C'. Já Ojima \& Rigitano (1970), em ambiente não nebulizado, obtiveram enraizamento de cerca de $3 \%$ para 'D'água'. A pereira 'Le Conte', segundo Barradas \& Koller (1976), destaca-se como sendo a de mais fácil enraizamento, com índices de 30 a $40 \%$. Os melhores resultados são citados por Simonetto (1990), que obteve enraizamento de $76 \%$ em estacas de 'Manshu Mamenashi' tratadas com AIB, na concentração de 3.000 ppm. Como se pode notar, o estímulo ao enraizamento de estacas lenhosas de pereira parece ser bastante complexo, mesmo lançando mão de modernas técnicas rizogênicas.

As estacas de 'Manshu Mamenashi' apresentaram baixa porcentagem de enraizamento em ambos os tratamentos, mostrando ser menos efetivas na propagação vegetativa em comparação com 'Taiwan Nashi-C' e 'D'água' (Tabela 1), para as condições do presente experimento. Esse fato pode ser justificado pela intensa brotação das estacas no período de enraizamento. Segundo Hartmann \& Kester (1990), a brotação antes do enraizamento ocasiona um consumo elevado das reservas nutricionais, prejudicando a emissão de raízes pela estaca.

Pela Tabela 1, pode verificar-se que houve diferença significativa entre os tratamentos com e sem incisão. Para o porta-enxerto ' $\mathrm{D}$ 'água', pode recomendar-se a incisão na base da estaca, que aumentou o enraizamento com o tratamento, porém o 'Taiwan Nashi-C' apresentou resultados superiores de enraizamento no tratamento sem incisão. Há relatos na literatura de que o ferimento da estaca ou a desobstrução da região entre o câmbio e o córtex pode estimular o desenvolvimento de primórdios radiculares (Krishnamoorthy, 1970); porém, a eficiência deste tratamento depende de cada espécie vegetal e das condições internas da planta-matriz (Hartmann \& Kester, 1990). Resultados mais significativos talvez possam ser alcançados, fazendo-se uso de incisões e imersões em promotores de enraizamento, a exemplo do AIB a 3.000 ppm, como relatado por Simonetto (1990). Assim, em estacas feridas, haveria maior superfície para absorção de reguladores de crescimento e formação de tecido rizogênico.

Com base nos resultados obtidos, pode-se concluir que: - Estacas lenhosas de 'Taiwan Nashi-C', sem incisão, apresentam enraizamento satisfatório quando mantidas sob ambiente de nebulização intermitente.

- O tratamento com incisão da pêra 'D'água' apresenta enraizamento satisfatório quando mantido sob nebulização intermitente.

- Estacas do porta-enxerto 'Manshu Mamenashi' não apresentam enraizamento satisfatório sob ambiente de nebulização intermitente, independentemente do uso ou não de incisão basal.

\section{AGRADECIMENTOS}

Os autores agradecem aos técnicos de apoio Marcilene de Moraes e Antonio Carlos de Carvalho e ao acadêmico Élcio

Rev. Bras. Frutic., Jaboticabal - SP, v. 24, n. 2, p. 583-585, agosto 2002 
de Oliveira, o auxílio na coleta, preparo e plantio das estacas.

\section{REFERÊNCIAS BIBLIOGRÁFICAS}

ANTUNES, L. E. C.; HOFMANN, A.; RAMOS, J. D.; CHALFUN, N. N. J.; OLIVEIRA JÚNIOR, A. F. Efeito de aplicação de concentração de ácido indolbutírico no enraizamento de estacas semilenhosas de Pyrus calleryana. Revista Brasileira de Fruticultura, Cruz das Almas, v.18, n.3, p.371-376, 1996.

BARBOSA, W.; CAMPO DALL'ORTO, F. A.; OJIMA, M.; MARTINS, F. P.; CASTRO, J. L.; MARTINS, A. L. M.; SANTOS, R. R. Formação rápida de mudas vigorosas de pêra com portaenxerto oriental. O Agronômico, Campinas, v.47-50, n.1, p.28-31, 1998.

BARRADAS, C. I. N; KOLLER, O. C.Cultura da macieira e da pereira. Porto Alegre: Universidade Federal de Pelotas, 1976. 90 $\mathrm{p}$ (apostila).

CHILDERS, F.N.; ZWET, T.V. The pear: cultivars to marketing. Florida: Horticultural Publishing, 1982. 501 p.

FACHINELLO, J.C.; HOFFMANN, A.; NACHTIGAL, J.C.; KERSTEN,E.; FORTES, G.R.L. Propagação de plantas frutíferas de clima temperado. 2. ed. Pelotas: UFPEL, 1995. 178 p.

HARTMANN, H.T.; KESTER, D. E. Propagacion de plantas: princípios y praticas. México: Compañia Editorial Continental, 1990.760p.
KRISHNAMOORTHY, H. N. Promotion of rooting in mung bean hypercotyl cuttings with etrehl, and ethylene releasing compound. Plant Cell Physiology, v.11, p.979-982, 1970.

MAEDA, J. A.; BARBOSA, W.; LAGO, A. A.; MEDINA, P. F.; CAMPO DALL'ORTO, F. A.; OJIMA, M. Métodos para superação da dormência e germinação de sementes da pereira portaenxerto 'Taiwan Nashi-C'. Revista Brasileira de Sementes, Brasília, v.19, n.2, p.271-275, 1997.

MASSERON, A. Les porte-greffe pommier, poirier et nashi. Paris: Centre Technique Interprofessionnel des Fruits et Légumes (CTIFL), 1989.297p.

OLIVEIRA, E. L.; BARBOSA, W.; MAIA, M. L. Análise dos mercados brasileiro e mundial de pêra. In: CONGRESSO BRASILEIRO DE FRUTICULTURA, 16., 2000, Fortaleza. Resumos ... Fortaleza, CE: SBF, 2000. p.523.

OJIMA, M.; RIGITANO, O. Clones para porta-enxerto da pereira. Bragantia, Campinas, v.29, n.26, p.287-292, 1970.

SIMONETTO, P. R. Propagação de Pyrus calleryana Dcne e Pyrus betulaefolia Bunge, porta-enxertos para pereira, através do processo de estaquia. 1990. 59f. Dissertação (Mestrado) FAEM/Universidade Federal de Pelotas, Pelotas, RS: 1990.

WESTWOOD, M. N. Temperate-zone pomology. San Francisco: W.H. Freeman, 1978. 428p. 